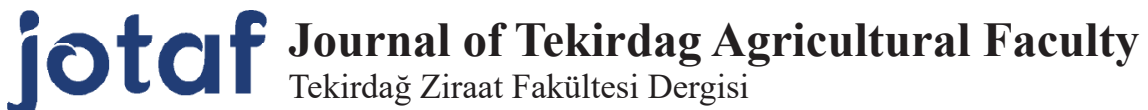

Mayı/May 2019, 16(2) Başvuru/Received: 12/03/19 Kabul/Accepted: 28/03/19 DOI: $10.33462 /$ jotaf.534428

http://dergipark.gov.tr/jotaf http://jotaf.nku.edu.tr/

\section{Tekirdağ Koşullarında Farklı Lateral Tertip Biçimi ve Sulama Suyu Uygulamalarının Genç Ceviz Ağaçlarının Su Kullanımı ve Vejetatif Gelişme Parametrelerine Etkileri*}

\author{
Effects of Different Lateral Layout and Irrigation Regimes on Water Use and Vegetative Growth \\ Parameters of Young Walnut Trees
}

\section{Erhan GÖÇMEN $^{\text {*** }}$, Tolga ERDEM ${ }^{1}$}

\section{$\ddot{O} z$}

Farklı lateral tertip biçimi ve sulama suyu uygulamalarının genç ceviz ağaçlarının ( 1 ve 2 . yaşında) su kullanımı ve vejetatif gelişme parametrelerine etkilerinin araştırıldığı çalışma 2015 ve 2016 yıllarında Tekirdağ koşullarında yürütülmüştür. Araştırmada, her ağaç sırasına çift sıra lateral tertip ve ağaç gövdesi etrafına sarılan salkım tertip olmak üzere iki farklı lateral tertip biçimi ve A sınıfı buharlaşma kabından ölçülen buharlaşma değerlerinin \%75, 100 ve 125' inin uygulandığı üç farklı sulama suyu uygulaması gerçekleştirilmiştir. Araştırma sonucunda, deneme konularında ölçüm periyodu boyunca ölçülen bitki su tüketimi değerleri uygulanan sulama suyu konularına bağlı olarak 2015 yılında 726.1 ile 983.9 mm, 2016 y1lında ise 604.9 ile $905.7 \mathrm{~mm}$ arasında değişmiştir. Araştırmada, ceviz ağaçlarının vejetatif gelişme parametreleri olarak gövde çap1, gövde kesit alanı, taç yüksekliği, taç genişliği ve taç hacmi değerleri değerlendirilmiştir. Bu değerler arasında yapılan varyans analiz sonuçlarına göre, farklı lateral tertip biçimi ve uygulanan sulama suyu miktarlarının ceviz ağaçlarının vejetatif gelişme parametrelerini istatistiksel olarak önemli derecede etkilemediği sonucuna varılmıştır.

Anahtar Kelimeler: Bitki su tüketimi, sulama suyu, vejetatif gelişme parametreleri, ceviz

\begin{abstract}
The experiment was conducted during the growing season 2015 and 2016 under Tekirdag conditions to evaluate the water use and vegetative growth parameters of young walnut trees ( 1 and 2 years old) under different lateral layout and irrigation water levels. In the study, two different lateral layouts as the double lateral lines per plant row and the loop system around the tree and three different irrigation water applications, $75 \%, 100$ and $125 \%$ of the evaporation values measured from Class A pan were applied. As a result of this study, the seasonal evapotranspiration in the treatments during the measurement period varied from 726.1 and $983.9 \mathrm{~mm}$ in 2015 and from 604.9 and $905.7 \mathrm{~mm}$ in 2016 depending on the irrigation water applied. The effects of walnut vegetative growth parameters as trunk diameter, trunk cross-sectional areas, canopy height, canopy width and canopy volume of the experimental subjects were investigated. Analyses of variance between group means showed that there were no statistically significant differences in the vegetative growth parameters according to the different lateral layout under different irrigation levels of walnut trees.
\end{abstract}

Keywords: Evapotranspiration, irrigation water, vegetative growth parameters, walnut

\footnotetext{
${ }^{1 * *}$ Sorumlu yazar/Corresponding Author: Erhan Göçmen, Tekirdağ Namık Kemal Üniversitesi Ziraat Fakültesi Biyosistem Mühendisliği Bölümü, Tekirdağ. E-mail: egocmen@nku.edu.tr, (DOrcID: 0000-0001-6199-7842

${ }^{1}$ Tolga Erdem, Tekirdağ Namık Kemal Üniversitesi Ziraat Fakültesi Biyosistem Mühendisliği Bölümü, Tekirdağ. E-mail: terdem@nku.edu.tr, (DOrcID: 0000-0002- 5887-9586

Atıf/Citation: Göçmen, E., Erdem, T. Tekirdağ koșullarında farklı lateral tertip biçimi ve sulama suyu uygulamalarının genç ceviz ağaçlarının su kullanımı ve vejetatif gelişme parametrelerine etkileri. Tekirdă̆ Ziraat Fakültesi Dergisi, 16(2), 181-191

*TÜBİTAK tarafindan 1140532 numara ile desteklenen projeden ve doktora tezinden üretilmiștir.

CBu çalışma Tekirdağ Namık Kemal Üniversitesi tarafından Creative Commons Lisansı (https://creativecommons.org/licenses/by-nc/4.0/) kapsamında yayınlanmıştır. Tekirdağ 2019
} 


\section{Extendend Summary}

Turkey is one of the most important countries in the world with regard to walnut production, but both production and export are not at the desired levels. Walnut is one of the important nut crops and the annual consumption per capita in Turkey is 2-3 kg. In addition, Turkey's annual walnut production is around 180000 tons while the import amounts about 40000 tons. The Ministry of Forestry and Water Affairs has put emphasis on walnut in afforestation work in recent years to increase the walnut production of Turkey. Approximately 110 thousand ha of the special walnut afforestation plan has been completed within 983 projects in Turkey so far and 2 million walnut trees have been planted (Anonymous, 2012). When new walnut areas were planted, the low yields obtained from the old areas were examined and it was stated that necessary researches should be conducted to overcome this. It has been proposed that these surveys concentrate on the standard walnut varieties as well as technical and cultural practices such as irrigation, fertilization, diseases and pests tolerance and making producers more conscious along with improving the cultural practices (Unver and Sakar, 2011; Anonymous, 2012). In this approach, irrigation is importance both in terms of plant productivity and conservation of natural resources. Şen (2011) stated that walnut trees are a common branching type of fruit species most in need of water in terms of having a large leaf surface. It explained that although walnut trees use partially natural rainfall, irrigation practices are important in terms of initial plant development. In the previous studies, irrigation applications for walnut trees at different vegetative periods were important and affected to yield and quality parameters (Şen, 2011; Huabing et al., 2014). Also, the drip irrigation method applications have been given best results on walnut trees (Hu et al., 2010; Li et al., 2013). Production to meet the domestic demand in recent years, closing with a private reforestation effort towards the establishment of walnut orchards incentives, the private sector has increased interest in the walnut growers. It is seen that in the last decade in Thrace Region walnut tis intensively being produced in areas which has lost its forest characteristics. Scarcity of water resources in the region and particularly heavily use of groundwater resources for irrigation purposes, the problems caused by irrigation in the cultivation of walnuts is widely observed. On the other hand, when the researches carried out in our country are examined, it has been determined that there is no work for the planning of water consumption and irrigation scheduling of walnut trees. The experiment was conducted during the growing season 2015 and 2016 under Tekirdag conditions to evaluate the water use and vegetative growth parameters of young walnut trees (1 and 2 years old) under different lateral layout and irrigation water amount applications. In the study, two different lateral layouts as the double lateral lines per plant row and the loop system around the tree and three different irrigation water applications, $75 \%, 100$ and $125 \%$ of the evaporation values measured from Class A pan were applied. As a result of this study, the seasonal evapotranspiration in the treatments during the measurement period varied from 726.1 and $983.9 \mathrm{~mm}$ in 2015 and from 604.9 and $905.7 \mathrm{~mm}$ in 2016 depending on the irrigation water applied. The effects of walnut vegetative growth parameters as trunk diameter, trunk cross-sectional areas, canopy height, canopy width and canopy volume of the experimental subjects were investigated. Variance analyzes of the obtained results showed that there were no statistically significant differences in the vegetative growth parameters according to the different lateral layout and irrigation levels of walnut trees. 
Türkiye, 2014 verilerine göre ceviz üretim alanlarında \%10.8 lik bir pay ile Çin, ABD ve İran ve Meksika'dan sonra beşinci sıradadır. Üretim miktarları açısından Çin ve ABD 'nin dünya ceviz üretiminin \%61.2'sini karşıladığı, İran'ın \%12.9 ile üçüncü, Türkiye'nin ise \%5.2 pay ile yine dördüncü, \%3.6 ile Meksika'nın beşinci, Ukrayna'nın \%3 ile altıncı sırada olduğu görülmektedir (FAO, 2014). Birbirlerine çok yakın ekim alanlarına sahip iki ülke olan Türkiye ve ABD üretim değerleri açısından karşılaştırıldığında, ABD üretiminin Türkiye üretiminin iki katı olduğu görülmektedir. Cevizin gen merkezi ve anavatanları içerisinde bulunan Türkiye ceviz varlığı olarak dünyada önemli bir konumda olmasına karşın, üretim ve ihracat yönünden beklenen noktada değildir. Türkiye 2015 yılında 7917 ton ihracat ve 63800 ton ithalat yapmıştır. Ülkemizde yıllık ceviz üretim miktarı 2016 verilerine göre 195000 ton civarında olup ağaç başına ortalama verimin ise $24 \mathrm{~kg}$ olduğu görülmektedir (Anonim 2016). Bu durumun AR-GE çalışmalarına çok geç başlamamız, aşılı çeşitlere daha yeni geçmemiz ve özellikle sulama, budama ve gübreleme işlemlerinin bilimselliğe ve tekniğine uygun yapılmamasından kaynaklandığı söylenebilir.

Trakya Bölgesi'nde, son on yılda orman vasfından çıkmış alanlarda yoğun bir şekilde ceviz yetiştiriciliğinin yapıldığı görülmektedir. Bununla beraber, Tekirdağ ilinde ceviz alanlarının hızla artmaya başladığı ve buna endeksli olarak üretiminde arttığı belirgin bir şekilde görülmektedir (Anonim 2016). Bu artışta orman vasfinı yitirmiş arazilerin üreticiye kiralanması, bakanlık desteklerinin olmasının yanında bölge çiftçisinin ekonomik değeri yüksek bitkileri yetiştirmeye yönelmesinin payı büyüktür. Üretimin önümüzdeki yıllarda daha da artması beklenmektedir. Çünkü mevcut alanlarda genç ağaç sayısının fazla olması ve meyve vermeyen ağaçların sayısının yüksek olması üretim değerini etkilemektedir. Ağaç yaşının ilerlemesiyle üretimin de artacağı beklenmektedir. İlde mevcut durumda 95970 adet meyve veren, 166648 adet meyve vermeyen olmak üzere 262618 adet ceviz ağacı bulunmaktadır. Ağaç başına ortalama verim 17 kg'dır (Anonim 2016). Ağaç başına verimi düşük olduğu görülen Tekirdağ' da, özellikle suyun alanda etkin kullanımı, sulamaların zamanında ve tekniğine uygun yapılması, budama, ilaçlama ve gübreleme işlemlerinin uygun bir biçimde yapılması ve ağacın olgunluk dönemlerine ulaşması verimi çok daha yükseltecektir.

Yapılan ağaçlandırma çalışmalarının ardından pek çok sıkıntının da beraberinde geldiği gerek çiftçiler gerekse uzmanlar tarafindan belirtilmektedir. En önemli problemlerden birisi sulama uygulamaları olarak ön plana çıkmaktadır. Su kaynaklarının azlığı, suyun alana iletilmesinde kurulacak sistemin yatırım maliyetlerinin yüksek oluşu suyun değerini daha da arttırmaktadır. Bunun yanında suyun bitkiye verilmesindeki yöntem farklılıkları da bitki gelişimi açısından standart olmamaktadır. Diğer yandan basınçlı sulama ekipmanlarının ilk yatırım masraflarının yüksek olması çiftçiyi daha geleneksel yöntemlere itmektedir. Bu zaten kıt olan suyun aşırı tüketilmesine neden olmaktadır. Ayrıca, uzman desteği alınmadan kurulan sistemlerde işletme problemlerinin meydana geldiği, bunun yanında sulama zamanının yanlış planlanması ve suyun eksik verilmesi vejetatif gelişmede noksanlıklara, fazla verilmesi ise köklerde mantari hastalıkların artmasına neden olduğu ortadadır (Anonim 2012).

Son yıllarda ceviz yetiştiriciliğine verilen öneme rağmen, bölgede sanayinin ve nüfusun artması kıymetli tarım toprakları ile su kaynaklarını azaltmış ve kirletmiştir. Ayrıca, sulama uygulamalarında yer altı su kaynaklarının yoğun olarak kullanıldığı düşünülürse ceviz yetiştiriciliğinde bölgede toprak ve su kaynakları açısından birçok problemin olduğu açıktır.

Tüm bu bilgiler 1şı̆̆ında ceviz, Tekirdağ çiftçisi için ciddi alternatif bir bitki olarak ön plana çıkmaktadır. Modern tarımın yapıldığı bölgede çiftçilerin yeniliğe son derece açık olduğu bilinmektedir. Son yıllarda ceviz üretim alanlarının 4 katına çıkması da pazar değeri yüksek olan bitkilere yönelimin bir göstergesidir. Geleneksel tarımı yapılan buğday ve ayçiçeğine göre ekonomik değerinin yüksek olmasının yanında, devlet tarafindan verilen destek ve hibeler bitkiyi önemli hale getirmektedir. Bunlara ilaveten bölgenin pazara yakınlığı da çok ciddi avantaj sağlamaktadır. Ayrıca damla sulamaya verilen desteklerin uygulayıcıları finansal olarak rahatlattığı görülmektedir. Çiftçilerin, su ve sulama konularındaki olumsuzlukları da ilde bulunan üniversite ile kamu kurum ve kuruluşlarından alınan bilgi ve desteklerle aşılmaktadır. Tüm bu avantajların yanında ceviz yetiştiriciliğinin artması, kaybolup giden orman alanlarının tekrar tesis edilmesine ve ülke ekonomisine büyük bir katkı sağlamaktadır.

Bu araştırma, Tekirdağ Bağcılık Araştırma Enstitüsü arazisinde yeni tesis edilen ceviz bahçesinde 2015 ve 2016 yıllarında yürütülmüş̧ür. Araştırmada, bölgede yoğun olarak tarımı yapılan Chandler çeşidi ceviz fidanları 2015 yılının ilk aylarında dikilmiştir. Araştırmada, bitkinin gelişimi, sulama sisteminin projelenmesi ve özellikle depolanacak su miktarının hesaplanması için gerekli olan su kullanımı değerlerinin eldesi amaçlanmıştır. Elde edilen tüm değerlerin, ülkemizde ceviz ağaçlarının su kullanımına yönelik ilk çalışma olması açısından önemlidir. Araştırma sonucunda elde edilen değerler, ceviz yetiştiriciliği açısından önemli olduğu kadar, azalan su kaynaklarının korunması açısından da önemlidir. 


\section{Materyal ve Yöntem}

Araştırma, Tekirdağ il merkezine 2.5 km uzaklıkta yer alan Tekirdağ Bağcılık Araştırma Enstitüsü Müdürlüğü arazisinde yürütülmüştür. Araştırma alanının denizden yüksekliği ortalama $4 \mathrm{~m}$, enlem derecesi $40^{\circ} 59^{\prime} \mathrm{kuzey,}$ boylam derecesi ise $27^{\circ} 29^{\prime}$ doğudur. Araştırma alanı yarı kurak bir iklim kuşağı içinde yer almaktadır. Uzun yıllar ortalamalarına göre, yıllık ortalama sıcaklık $13.9^{\circ} \mathrm{C}$ ' dir. Aylık sıcaklık ortalamaları açısından en soğuk ay $4.7^{\circ} \mathrm{C}$ ile Ocak, en sıcak ay ise $23.8^{\circ} \mathrm{C}$ ile Temmuz aylarıdır. Yıllık ortalama yağış miktarı $580.8 \mathrm{~mm}$ olmasına karşın, bunun büyük bir kısmı Ekim ile Nisan ayları arasındaki dönemde gerçekleşmektedir. Yıllık ortalama bağıl nem \%76.9' dur. Yıllık ortalama rüzgâr hızının 2 m yükseklikteki değeri 2.90 m/s' dir.

Araştırmanın yürütüldüğü Tekirdağ Bağcılık Araştırma Enstitüsü Müdürlüğü toprakları killi tınlı bünyeye sahip, hafif tuzlu, az kireçli ve organik madde içeriği düşük topraklardan oluşmaktadır. Alanda eğim batıdan doğuya doğrudur. Eğim batı kesimlerde oldukça yüksek olup \%15 dolayında, doğu kesimlerde ise \%1,5 civarındadır.

Denemede kullanılan sulama suyu Enstitüde bulunan dereden ve kuyudan sağlanmış, su önce havuzda toplanmış, bir pompa yardımıyla alana iletilmiş ve uygulama damla sulama yöntemiyle gerçekleştirilmiştir. Depolama havuzundan pompa ile alınan sulama suyu, hidrosiklon, kum-çakıl filtre tankı ve disk elek filtrelerden oluşan kontrol biriminden geçtikten sonra 6 atm işletme basınçlı, $50 \mathrm{~mm}$ dış çaplı sert PE borular yardımı ile araştırma alanına iletilmiştir. Ayrıca, sistemde oluşan basıncı kontrol etmek amacıyla manometreler yerleştirilmiştir. Her bir deneme parseli için manifold boru hatları $40 \mathrm{~mm}$ dış çaplı sert PE borulardan oluşturulmuştur. Deneme parselleri içerisinde iki farklı damla sulama hattı döșenmiştir. İlki her ağaç sırasına 16 mm diş çaplı yumuşak PE borulardan oluşan çift sıra lateral boru hattı, ikincisi tek sıra lateral boru hattı üzerinden ağaçlara çıkış yapılarak döşenen ve 16 mm dış çaplı yumuşak PE borulardan oluşan salkım hat tertip edilmiştir. Ceviz ağaçlarının araştırma sırasında yeni tesis edilmesinden dolayı bitki sıra arası ve üzerinde tam örtme yapmadığından tüm lateral boru hattı 1slatılmamıştır. $\mathrm{Bu}$ nedenle her ağaç başına taç genişliği dikkate alınarak karşılıklı olmak üzere 3'er adetten toplam 6 adet basınç regüleli on-line damlatıcı yerleştirilmiştir. Salkım tertipte de yine ağaç tacı dikkate alınarak ağaç çevresine 6 adet damlatıcı yerleştirilmiştir. Damlatıcı debisi Yıldırım (2008)' de belirtilen esaslara göre toprağın bünyesi ve su alma hızı dikkate alınarak 4 L/h olarak seçilmiştir. Deneme parsellerinin ayrıntısı Şekil 1 ve Şekil 2’ de verilmiştir.

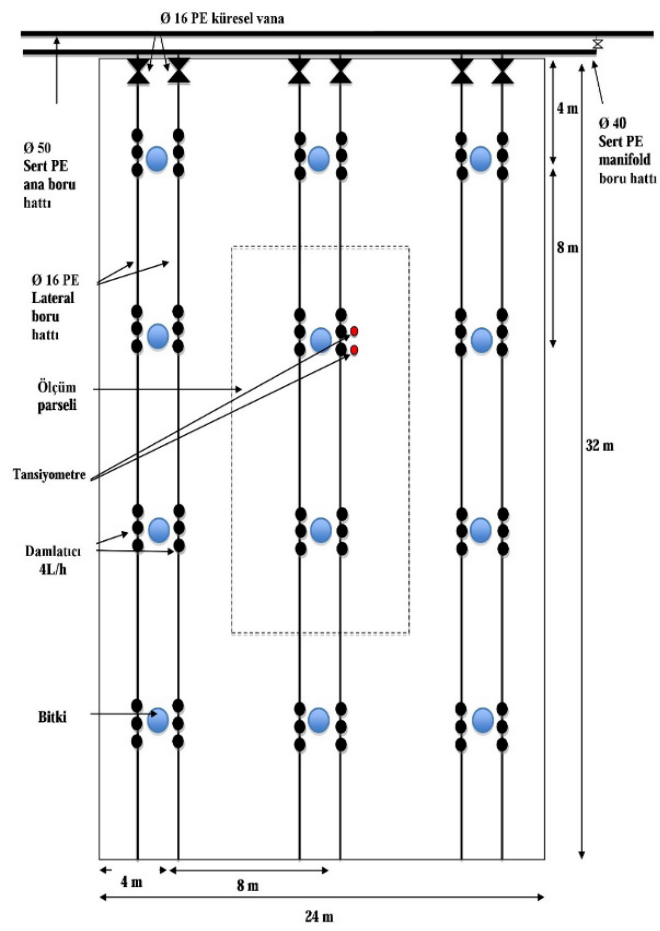

Şekil 1. Çift sıra lateral tertip damla sulama sistemi Figure 1. Double lateral line in layout for treatment

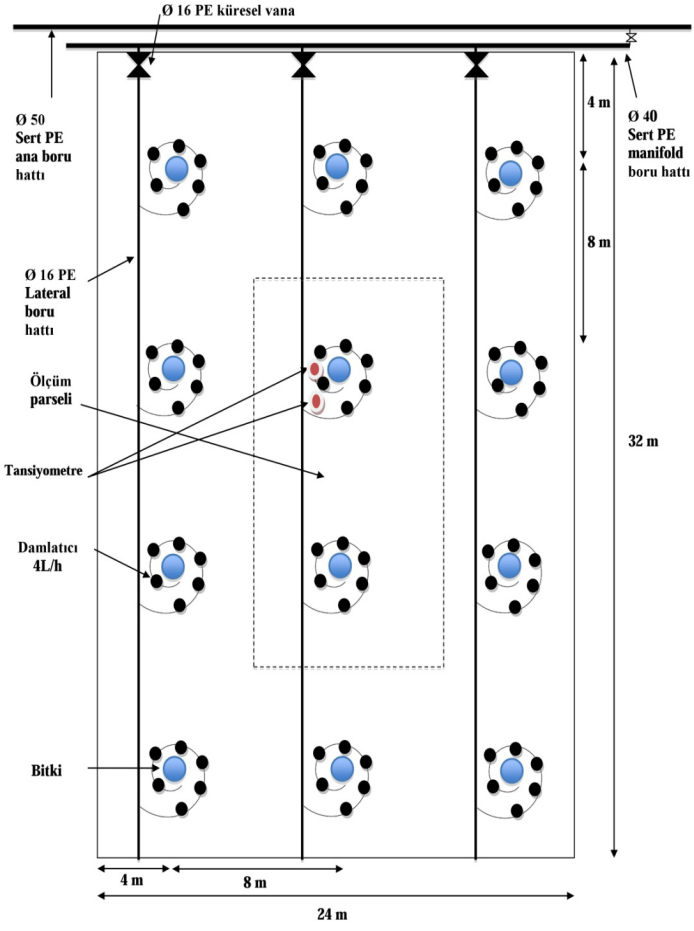

Şekil 2. Salkım lateral tertip damla sulama sistemi Figure 2. Loop system in layout for treatment

Araştırmada Tübitak Projesi kapsamında Tekirdağ Bağcılık Araştırma Enstitüsü Müdürlüğü arazisine Chandler çeşidi ağaçlar 2015 yılının Mart ayı başında 8x8 m sıra arası ve sıra üzeri genişliklerinde dikilmiştir (Şekil 3.9). 
Ceviz ağaçlarının dikiminden itibaren bitkisel gözlemleri yapılmış ve buharlaşmanın arttığı Mayıs ayı sonlarında sulama uygulamaları damla sulama yöntemi ile uygulanmaya başlanmıştır. Araştırma ceviz ağaçlarının 1 ve 2. yaşlarında olduğu 2015 ve 2016 yıllarında yürütülmüştür.

Araştırmada deneme konuları belirlenirken, proje sonucunda elde edilen değerlerin uygulayıcılar tarafından rahatlıkla kullanılabilmesi göz önüne alınmıştır. Araştırmada ceviz ağaçları için iki farklı damla sulama tertip biçimi ana konu olarak dikkate alınmıştır (Nakayama ve Bucks 1986, Keller ve Bliesner 1990, Yıldırım 2008). Deneme konular1,

$\mathrm{D}_{1}$ : Her ceviz sırasına çift sıra lateral hattı yerleştirilmiştir. Lateral hatları üzerinde toprağın infiltrasyon hızına göre belirlenen damlatıcı aralığına göre $(50 \mathrm{~cm})$ her ağacın taç genişliği kadar damlatıcı (6 adet) yerleştirilmiştir.

$\mathrm{D}_{2}$ : Her ağaca salkım tipi damla sulama uygulaması yapılmıştır. Salkım tipinde yerleştirecek damlatıcı sayısı $\mathrm{D}_{1}$ konusu ile aynı olmuştur.

Alt deneme konuları, 5 gün sulama aralığında A sınıfı buharlaşma kabından ölçülen açık su yüzeyi buharlaşma miktarının farklı düzeylerinin uygulanacağı şekilde hazırlanmıştır. Sulama aralığı ise bitki özellikleri ve bölge koşullarında ceviz yetiştiriciliği yapan üreticilerin uygulama koşulları incelenerek 5 gün olarak belirlenmiştir. Böylece alt deneme konuları,

I konusu: Toplam buharlaşma miktarının \%75'nin uygulandığı sulama uygulaması,

I konusu: Toplam buharlaşma miktarının \%100’ nün uygulandığı sulama uygulaması,

$\mathrm{I}_{3}$ konusu: Toplam buharlaşma miktarının \%125’nin uygulandığı sulama uygulaması biçiminde düzenlenmiştir.

Deneme alanı 72x192 m boyutlarında olup, toplam $13824 \mathrm{~m}^{2}$ dir. Bir deneme parseli 24x32 m boyutlarında olmak üzere toplam $432 \mathrm{~m}^{2}$ alana sahiptir. Bir deneme parselinde 3 adet ağaç sırası bulunmaktadır. Ağaçların sıra aralığı ve sıra üzeri 8 m’ dir. Tüm parsellerde birer ağaç sırası kenar etkisi göz önüne alınarak hasat parseli dışında bırakılmıştır. Her deneme parselindeki ağaç sayısı 12, ölçüm parselinde ise 2 adettir.

Deneme parsellerinde sulama suyu uygulama aralı̆̆ının belirlenmesinde, bölge çiftçisinin uygulamaları ve bitki özellikleri dikkate alınarak 5 gün sulama aralığının uygun olabileceğine karar verilmiştir ve uygulanacak sulama suyu miktarı 5 günlük yığışımlı buharlaşma değerleri kullanılarak aşağıdaki eşitlik yardımıyla hesaplanmıştır (Kanber ve ark. 2004).

$$
\mathrm{I}=\mathrm{K}_{\mathrm{pc}} \times \mathrm{E}_{\mathrm{p}} \times \mathrm{P}
$$

Eşitlikte; I: uygulanacak sulama suyu miktarı $(\mathrm{mm}), \mathrm{K}_{\mathrm{pc}}$ : buharlaşma kabına bağlı katsayı, $\mathrm{E}_{\mathrm{p}}$ : yı̆̆ģ̧ıิmlı buharlaşma miktarı, (mm), P: damlatıcı aralığı ve lateral aralığına göre belirlenen sslatılan alan yüzdesi (\%), dir.

Bitki su tüketimi değerleri, bitki etkili kök derinliğine göre aşağıda verilen su bütçesi yaklaşımı ile hesaplanmıştır (Walker ve Skogerboe 1987). Bu amaçla, sulama uygulaması öncesi her bir deneme konusunda iki adet parselde $90 \mathrm{~cm}$ toprak derinliğinde her $30 \mathrm{~cm}$ ' lik toprak katmanı için kuru ağırlık yüzdesine göre toprak nemi ölçülmüştür.

$$
E T=I+P+C_{p}-D_{p} \pm R_{f} \pm \Delta S
$$

Eşitlikte; ET: Bitki su tüketimi (mm),I: periyot boyunca uygulanan sulama suyu miktarı (mm), P: periyot boyunca düşen yağış $(\mathrm{mm}), \mathrm{C}_{\mathrm{p}}$ : kılcal yükselişle kök bölgesine giren su miktarı $(\mathrm{mm}), \mathrm{D}_{\mathrm{p}}$ : derine sızma kayıpları $(\mathrm{mm}), \mathrm{R}_{\mathrm{f}}$ : deneme parsellerine giren ve çıkan yüzey akış miktarı $(\mathrm{mm}), \Delta \mathrm{S}$ : kök bölgesindeki toprak nemindeki değişimler (mm), değerlerini göstermektedir.

Deneme alanında taban suyu bulunmadığından, kılcal hareketle bitki kök bölgesine su girişi olmadığı varsayılarak $\mathrm{C}_{\mathrm{p}}$ değeri göz önüne alınmamıştır. Ayrıca, basınçlı sulama sistemi kullanıldığından yüzey akış miktarları da ihmal edilmiştir (Kanber 1997). Derine sızma kayıpları için bir alt katman izlenmiştir.

Araştırmanın birinci yılı sonunda ağaçlar $80 \mathrm{~cm}$ yukarıdan budandığı için gövde çapı ve gövde kesit alanı hariç diğer parametreler denemenin sadece ikinci yılı için belirlenmiştir. Taç genişliği ve taç yüksekliği değerleri ağaçların kış dinlenmesine geçtikleri zaman ölçülmüş ve taç hacimleri hesaplanmıştır (Köksal 1982; Çelik 1988). Deneme parsellerindeki her iki ölçüm ağacı, aşı yerlerinden 15-20 cm kadar yukarıda işaretlenmişlerdir. Denemenin kurulduğu an ve sulama sezonlarının sonunda, ağaçlar kış dinlenmesine girdiği zaman işaretli yerlerden 
iki yönlü olacak şekilde gövde çapı ölçümleri kumpas kullanılarak belirlenmiş ve gövde kesit alanı değerleri hesaplanmıştır (Yıldııım, 2004). Her sulama sezonu sonu bir önceki yıldan çıkartılarak gövde kesit alanı artış miktarları hesaplanmıştır (Köksal ve ark. 1996). Deneme konularından elde edilen vejetatif gelişme parametreleri arasındaki farklılıkların düzeyinin belirlenmesinde varyans analizi, farklıkların sınıflandırılmasında ise LSD testi kullanılmıştır. Elde edilen veriler Yurtsever (1984)' de açıklanan esaslara göre değerlendirilmiştir.

\section{Bulgular ve Tartışma}

Araştırma alanında iki farklı profilden alınan toprakların fiziksel özellikleri; bünye sınıfı, hacim ağırlığı, tarla kapasitesi, solma noktası ve kullanılabilir su tutma kapasitesi değerlerinin ortalaması Çizelge 1' de verilmiştir. Araştırma alanının toprak bünye sınıfı kil veya killi-tın, kullanılabilir su tutma kapasitesi $120.12 \mathrm{~mm} / 90 \mathrm{~cm}$ olarak bulunmuştur. Çift silindir infiltrometre ölçmeleri sonucunda toprağın gerçek su alma hızı değeri ortalama olarak $12 \mathrm{~mm} / \mathrm{h}$ alınmıştır. Sulama suyu kalite sınıfı $\mathrm{T}_{2} \mathrm{~S}_{1}$ olarak belirlenmiştir ve sulama suyu analiz sonuçlarının bitki gelişmesini olumsuz etkileyecek özelliklerde olmadığı görülmektedir. Araştırma alanı topraklarının bünye sınıfı ve gerçek infiltrasyon hızı değerlerine göre damlatıcı debisi $4 \mathrm{~L} / \mathrm{h}$, damlatıcı aralığı ise $0.50 \mathrm{~m}$ olarak seçilmiş̧ir.

Çizelge 1. Araştırma alanı topraklarının fiziksel özellikleri

Table 1. The physical characteristics of soil at the experimental site

\begin{tabular}{cccccccc}
\hline \multirow{2}{*}{$\begin{array}{c}\text { Profil } \\
\text { Derinliği } \\
(\mathrm{cm})\end{array}$} & $\begin{array}{c}\text { Bünye } \\
\text { sınıfi }\end{array}$ & \multicolumn{2}{c}{ Tarla kapasitesi } & Solma noktas1 & $\begin{array}{c}\text { Hacim } \\
\text { Ağıllı̆1 } \\
\left(\mathrm{g} / \mathrm{cm}^{3}\right)\end{array}$ & $\begin{array}{c}\text { Kullanilabilir } \\
\text { su tutma } \\
\text { kapasitesi } \\
(\mathrm{mm})\end{array}$ \\
\hline $0-30$ & Killi-tın & 26.01 & 116.26 & 17.91 & 80.06 & 1.49 & 36.20 \\
\hline $30-60$ & Killi-tın & 28.45 & 134.85 & 19.71 & 93.43 & 1.58 & 41.42 \\
\hline $60-90$ & Kil & 31.76 & 153.40 & 22.96 & 110.90 & 1.61 & 42.50 \\
$90-120$ & Kil & 30.17 & 143.01 & 21.15 & 100.25 & 1.58 & 42.76 \\
\hline $0-90$ & & & 404.51 & & 284.39 & & 120.12 \\
$0-120$ & & & 547.52 & & 384.64 & & 162.36 \\
\hline
\end{tabular}

Denemenin ilk yllında toprak nem ölçümlerine 23 Mart 2015 tarihinde başlanmış ve 5 Ekim 2015 tarihinde sonlandırılmıştır. Sulama uygulamalarına ise 2 Haziran 2015 tarihinde başlanmış ve en son sulama uygulaması 17 Eylül 2015 tarihinde yapılmıştır. Sulama sezonu boyunca A sınıfı buharlaşma kabından ölçülen toplam açık su yüzeyi buharlaşma miktarı 29 Mayıs 2015 ile 17 Eylül 2015 tarihleri arasında $595.6 \mathrm{~mm}$ olmuştur. Dolayısıyla, A sınıfı buharlaşma kabından ölçülen açık su yüzeyi buharlaşma miktarının \%100'nün uygulandığı $\mathrm{I}_{2}$ deneme konusuna uygulanan toplam sulama suyu miktarları da $595.6 \mathrm{~mm}$ olmuştur. Diğer yandan ölçülen açık su yüzeyi buharlaşma miktarııı $\% 75^{\prime}$ inin uygulandığ $\mathrm{I}_{1}$ deneme konusuna $446.7 \mathrm{~mm}, \% 125^{\prime}$ inin uygulandığı $\mathrm{I}_{3}$ deneme konusuna ise $744.5 \mathrm{~mm}$ toplam sulama suyu uygulanmıştır. Deneme konularına $21 \mathrm{kez} 5$ gün sulama aralığında ve $2 \mathrm{kez} 4$ gün sulama aralı̆̆ında olmak üzere toplam 23 sulama uygulaması yapılmıştır. Sulama aralı̆̆ı boyunca ölçülen açık su yüzeyi buharlaşma miktarları 19.3 ile $36.6 \mathrm{~mm}$ arasında değişmiş̧ir. En yüksek açık su yüzeyi buharlaşma miktarı 19 Temmuz tarihinde $36.6 \mathrm{~mm}$ ile ölçülmüştür. Ayrıca, toprak nem ölçümlerinin başlandığı 23 Mart 2015 tarihi ile sonlandırıldığı 5 Ekim 2015 tarihleri arasında 209.0 mm yağış kaydedilmiştir. Toprak nem ölçümleri, sulama uygulamaları başlanıncaya kadar hava koşullarının elverdiği sürece, sulama uygulamalarının başlaması ile birlikte ise sulama öncesinde gravimetrik yönteme göre yapılmıştır. Her bir deneme konusu için elde edilen $90 \mathrm{~cm}$ toprak derinliği için kuru ağırlık cinsinden hesaplanan toprak nemi değerleri, uygulanan sulama suyu miktarları, ölçülen yağı̧ değerleri dikkate alınarak elde edilen bitki su tüketimi değerleri 2015 yılı için Çizelge 2' de verilmiştir. Çizelge incelendiğinde, deneme konuları arasında ölçüm periyodu boyunca toplam bitki su tüketimi $726.1 \mathrm{~mm}$ ile $983.9 \mathrm{~mm}$ arasında değişmiştir. A sınıfı buharlaşma kabından ölçülen açık su yüzeyi buharlaşma miktarının \%100'nün uygulandığ $\mathrm{I}_{2}$ deneme konularında $858.9 \mathrm{~mm}$ ve $862.2 \mathrm{~mm}$ bitki su tüketimi değeri elde edilmiştir. Açık su yüzeyi buharlaşma miktarının \%75' inin uygulandığı $\mathrm{I}_{1}$ deneme konusunda 732.8 mm ile $726.1 \mathrm{~mm}$ olarak ölçülen bitki su tüketimi, \%125' inin uygulandığ $\mathrm{I}_{3}$ deneme konusunda ise $978.9 \mathrm{~mm}$ ile 983.9 mm olarak ölçülmüştür. Böylece, uygulanan sulama suyu miktarı arttıkça ölçülen bitki su tüketiminin arttı̆̆ 1 görülmüsşür. Diğer yandan sulama uygulamaları öncesinde her bir deneme konusunda $90 \mathrm{~cm}$ derinlikte ölçülen mevcut toprak nemi değerleri Şekil 3’te verilmiştir. Şekilden görüleceği gibi, sulama öncesi toprak nemi değişimleri uygulanan sulama suyu miktarına bağlı olarak değişmiştir. Sulama öncesi toprak nemi değerlerinin tarla kapasitesi ile solma noktası değerleri arasında kaldığı görülebilir. Fakat sulama sezonunun sonlarına doğru sulama öncesi mevcut toprak neminin solma noktasında yaklaşı̆̆ı görülebilir. Bu sonuç, ağaçların bir yaşında olması nedeniyle 
örtü yüzdesinin düşük olması ve topraktan olan buharlaşma miktarının yüksek olmasına bağlanabilir. Farklı lateral tertip biçimleri incelendiğinde ise hem çift sıra hem de salkım tertip biçimlerinde ölçülen bitki su tüketimlerinin birbirlerine yakın olduğu görülmüştür.

Çizelge 2. Deneme konularına uygulanan sulama suyu ve ölçülen bitki su tüketimi değerleri (2015)

Table 2. Applied irrigation water and measured seasonal evapotranspiration for treatments (2015)

\begin{tabular}{cccccc}
\hline \multicolumn{2}{c}{ Deneme Konuları } & Topraktaki nem & Yağ1ş \\
$\begin{array}{c}\text { Lateral tertip } \\
\text { biçimi }\end{array}$ & $\begin{array}{c}\text { Sulama suyu } \\
\text { miktarları }\end{array}$ & $\begin{array}{c}\text { Uygulanan } \\
\text { sulama suyu } \\
(\mathrm{mm})\end{array}$ & $\begin{array}{c}\text { Ölçülen bitki su } \\
\text { tüketimi } \\
(\mathrm{mm})\end{array}$ \\
\hline $\begin{array}{c}\text { Çift sıra } \\
\left(\mathrm{D}_{1}\right)\end{array}$ & $\mathrm{I}_{1}$ & 76.7 & & 447.1 & 732.8 \\
& $\mathrm{I}_{2}$ & 54.4 & 209.0 & 595.6 & 858.9 \\
\hline Salk1m & $\mathrm{I}_{3}$ & 25.0 & & 744.9 & 978.9 \\
$\left(\mathrm{D}_{2}\right)$ & $\mathrm{I}_{1}$ & 70.0 & & 447.1 & 726.1 \\
& $\mathrm{I}_{2}$ & 57.7 & 209.0 & 595.6 & 862.2 \\
\hline
\end{tabular}

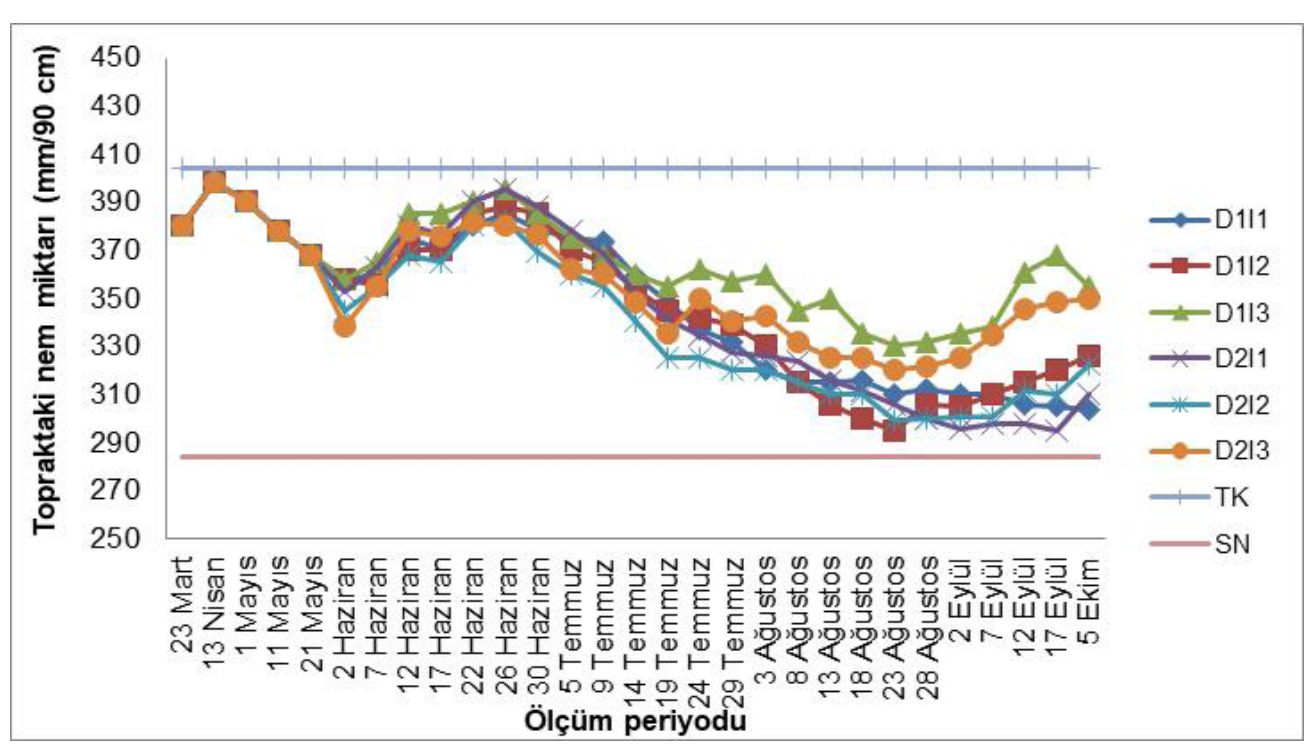

Şekil 3. Bitki gelişim periyodu boyunca sulama öncesi topraktaki nem değişimleri, (2015 yılı)

Figure 3. Moisture changes in the soil before irrigation during the plant growth period, (2015 year)

Araştırmanın 2. yılı için sulama uygulamalarına 25 Mayıs 2016 tarihinde başlanmış ve en son sulama uygulaması 7 Eylül 2016 tarihinde yapılmıştır. Sulama sezonu boyunca A sınıfı buharlaşma kabından ölçülen toplam açık su yüzeyi buharlaşma miktarı 21 Mayıs 2016 ile 7 Eylül 2016 tarihleri arasında 585.9 mm olmuştur. Dolayısıyla, A sınıfı buharlaşma kabından ölçülen açık su yüzeyi buharlaşma miktarının \%100'nün uygulandığı $\mathrm{I}_{2}$ deneme konusuna uygulanan toplam sulama suyu miktarları $585.9 \mathrm{~mm}$ olmuştur. Diğer yandan ölçülen açık su yüzeyi buharlaşma miktarının \%75' inin uygulandığı $\mathrm{I}_{1}$ deneme konusuna 439.6 mm, \%125' inin uygulandığı $\mathrm{I}_{3}$ deneme konusuna ise $732.4 \mathrm{~mm}$ toplam sulama suyu uygulanmıştır. Deneme konularına, projede öngörüldüğü üzere 5 gün sulama aralığında toplam 22 sulama uygulaması yapılmıştır. Sulama aralığı boyunca ölçülen açık su yüzeyi buharlaşma miktarları 10.1 ile $36.8 \mathrm{~mm}$ arasında değişmiştir. Ayrıca, toprak nem ölçümlerinin başlandığ 1 Nisan 2016 tarihi ile sonlandırıldığı 6 Ekim 2016 tarihleri arasında 81 mm yağış kaydedilmiştir. Toprak nem ölçümlerine 1 Nisan 2016 tarihinde başlanmış ve 6 Ekim 2016 tarihinde sonlandırılmıştır. Her bir deneme konusu için elde edilen $90 \mathrm{~cm}$ toprak derinliği için kuru ağırlık cinsinden hesaplanan toprak nemi değerleri, uygulanan sulama suyu miktarları, ölçülen yağış değerleri dikkate alınarak elde edilen bitki su tüketimi değerleri Çizelge 3' de verilmiştir. Toplam bitki su tüketimi $604.9 \mathrm{~mm}$ ile $905.7 \mathrm{~mm}$ arasında değişmiştir. A sınıfı buharlaşma kabından ölçülen açık su yüzeyi buharlaşma miktarının \%100’ ün uygulandığı I deneme konularında 757.5 mm ve 764.5 mm bitki su tüketimi değeri elde edilmiştir. Açık su yüzeyi buharlaşma miktarının \% 75 ' inin uygulandığı $\mathrm{I}_{1}$ deneme konusunda $604.9 \mathrm{~mm}$ ile $615.9 \mathrm{~mm}$ olarak ölçülen bitki su tüketimi, \%125' inin uygulandığg $\mathrm{I}_{3}$ deneme konusunda ise $899.0 \mathrm{~mm}$ ile $905.7 \mathrm{~mm}$ olarak ölçülmüştür. Böylece uygulanan sulama suyu miktarı arttıkça ölçülen bitki su 
tüketiminin arttığı görülmüştür. Denemenin ikinci yılında da farklı lateral tertip biçimleri incelendiğinde ise birinci yılda olduğu gibi hem çift sıra hem de salkım tertip biçimlerinde ölçülen bitki su tüketimlerinin birbirlerine yakın olduğu görülmüştür. Diğer yandan sulama uygulamaları öncesinde her bir deneme konusunda $90 \mathrm{~cm}$ derinlikte ölçülen mevcut toprak nemi değerleri Şekil 4'de verilmiştir. Şekilden görüleceği gibi, sulama öncesi toprak nemi değişimleri uygulanan sulama suyu miktarına bağlı olarak değişmiştir. Sulama öncesi toprak nemi değerlerinin tarla kapasitesi ile solma noktası değerleri arasında kaldığı görülebilir. Sulama öncesi toprak nem değişimlerinin denemenin ikinci yılında birinci yıla oranla ölçüm periyodu boyunca standart bir eğilim izlediği görülmektedir. Bunun nedeni olarak, ceviz ağaçlarının vejetatif gelişimlerinin hızlanması dolayışla örtü yüzdesinin artması ve topraktaki buharlaşma miktarının azalması söylenebilir.

Çizelge 3. Deneme konularına uygulanan sulama suyu ve ölçülen bitki su tüketimi değerleri (2016)

Table 3. Applied irrigation water and measured seasonal evapotranspiration for treatments (2016)

\begin{tabular}{|c|c|c|c|c|c|}
\hline \multicolumn{2}{|c|}{ Deneme Konuları } & \multirow{2}{*}{$\begin{array}{l}\text { Topraktaki nem } \\
\text { değişimi (mm) }\end{array}$} & \multirow{2}{*}{$\begin{array}{l}\text { Yağ1Ş } \\
(\mathrm{mm})\end{array}$} & \multirow{2}{*}{$\begin{array}{l}\text { Uygulanan } \\
\text { sulama suyu } \\
(\mathrm{mm})\end{array}$} & \multirow{2}{*}{$\begin{array}{l}\text { Ölçülen bitki su } \\
\text { tüketimi } \\
(\mathrm{mm})\end{array}$} \\
\hline $\begin{array}{l}\text { Lateral tertip } \\
\text { biçimi }\end{array}$ & $\begin{array}{l}\text { Sulama suyu } \\
\text { miktarları }\end{array}$ & & & & \\
\hline \multirow{3}{*}{$\begin{array}{l}\text { Çift sıra } \\
\left(\mathrm{D}_{1}\right)\end{array}$} & $\mathrm{I}_{1}$ & 95.3 & \multirow{3}{*}{81.0} & 439.6 & 615.9 \\
\hline & $\mathrm{I}_{2}$ & 90.6 & & 585.9 & 757.5 \\
\hline & $\mathrm{I}_{3}$ & 92.3 & & 732.4 & 905.7 \\
\hline \multirow{3}{*}{$\begin{array}{l}\text { Salkım } \\
\left(\mathrm{D}_{2}\right)\end{array}$} & $\mathrm{I}_{1}$ & 84.3 & \multirow{3}{*}{81.0} & 439.6 & 604.9 \\
\hline & $\mathrm{I}_{2}$ & 97.6 & & 585.9 & 764.5 \\
\hline & $\mathrm{I}_{3}$ & 85.6 & & 732.4 & 899.0 \\
\hline
\end{tabular}

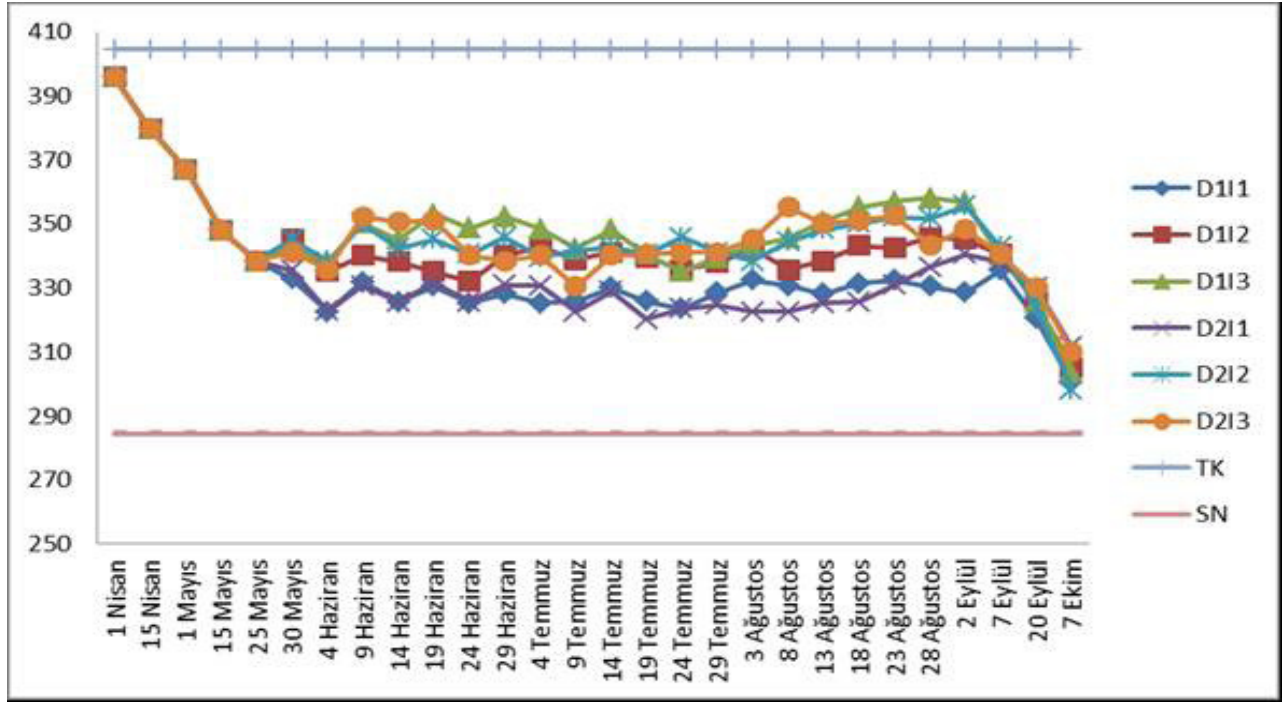

Şekil 4. Bitki gelişim periyodu boyunca sulama öncesi topraktaki nem değişimleri, (2016 yılı)

Figure 4. Moisture changes in the soil before irrigation during the plant growth period, (2016 yll)

Farklı lateral tertip biçimi ve farklı sulama düzeylerinin ceviz ağaçlarının vejetatif gelişme parametrelerine olan etkisini belirlemek için sulamanın tamamlanıp bitkilerin kış dinlenmesine geçtiği zaman ceviz ağaçlarında vejetatif gelişme parametresi ölçümleri yapılmıştır. Bu parametrelerden gövde çapı sadece birinci yılda ölçülmüş gövde çap değişimleri ile hesaplanan gövde kesit alanı değerleri elde edilmiştir. Denemenin ikinci yılında gövde çapı ölçümlerinin yanı sıra taç yüksekliği, taç genişliği ve bunlardan hesaplanan taç hacmi sonuçları belirlenmiştir. Deneme konularından ölçülen ceviz ağaçları vejetatif gelişme parametreleri 2015 yılı için Çizelge 4 ve 2016 yılı için Çizelge 5' de özetlenmiştir. Çizelgelerden görüleceği gibi deneme konularında elde edilen gövde çapı değerleri denemenin birinci yılında 2.05 ile $2.62 \mathrm{~cm}$ arasında değişirken, denemenin ikini yılında ise 4.00 ile 4.73 $\mathrm{cm}$ arasında değişmiştir. Ayrıca gövde çapına göre hesaplanan gövde kesit alanı artış değerleri 2015 yılında 2.48 ile $4.04 \mathrm{~cm}^{2}$, 2016 yılında ise 8.17 ile $12.15 \mathrm{~cm}^{2}$ arasında değişmiştir. Diğer yandan deneme konuları arasında en yüksek gövde çapı ve gövde kesit alanı değerlerinin çift sıra lateral tertip biçiminde A sınıfı buharlaşma kabından 
ölçülen açık su yüzeyi buharlaşma miktarının \%100' ünün uygulandığı deneme konusundan $\left(\mathrm{D}_{1} \mathrm{I}_{2}\right)$ elde edildiği görülmüştür. Deneme konularında elde edilen gövde çapına ve gövde kesit alanı artış miktarına ilişkin yapılan varyans analizi sonuçları incelediğinde, farklı lateral tertip biçiminin ve uygulanan sulama suyu miktarları arasında istatistiksel açıdan önemli farklar bulunmamıştır. Denemenin ikinci yılında ölçülen taç yüksekliği değerleri 1.68 ile $2.07 \mathrm{~m}$, taç genişliği değerleri 1.16 ile $1.35 \mathrm{~m}$ ve bu değerlere göre hesaplanan taç hacmi değerleri 0.91 ile $1.57 \mathrm{~m}^{3}$ arasında değişmiştir. En yüksek taç yüksekliği, taç genişliği ve taç hacmi değerleri salkım lateral tertip biçiminde A sınıfı buharlaşma kabından ölçülen açık su yüzeyi buharlaşma miktarının $\% 125$ ' ünün uygulandığı deneme konusundan $\left(\mathrm{D}_{2} \mathrm{I}_{3}\right)$ elde edildiği görülmüş̧ür. Bu değerler için yapılan varyans analiz sonuçlarına göre ise istatistiksel açıdan önemli farklar elde edilmemiştir.

Çizelge 4. Deneme konularından ölçülen ceviz ağaçları vejetatif gelişme parametreleri (2015)

Table 4. The measured walnut vegetative growth parameters for treatments (2015)

\begin{tabular}{|c|c|c|c|}
\hline \multicolumn{2}{|c|}{ Deneme Konuları } & \multirow{2}{*}{$\begin{array}{l}\text { Sulama sezonu sonunda } \\
\text { ölçülen gövde çapı değerleri } \\
(\mathrm{cm})\end{array}$} & \multirow{2}{*}{$\begin{array}{r}\text { Sulama sezonu sonunda } \\
\text { elde edilen gövde kesit } \\
\text { alanı artı̧ değerleri }\left(\mathrm{cm}^{2}\right)\end{array}$} \\
\hline Lateral tertip biçimi & $\begin{array}{c}\text { Sulama suyu } \\
\text { miktarları }\end{array}$ & & \\
\hline & $\mathrm{I}_{1}$ & $2.18 \mathrm{~ns}$ & $2.64 \mathrm{~ns}$ \\
\hline & $\mathrm{I}_{2}$ & 2.62 & 4.04 \\
\hline Çift sıra $\left(D_{1}\right)$ & $\mathrm{I}_{3}$ & 2.41 & 3.28 \\
\hline \multirow{3}{*}{$\begin{array}{l}\text { Salkım } \\
\left(\mathrm{D}_{2}\right)\end{array}$} & $\mathrm{I}_{1}$ & 2.36 & 3.03 \\
\hline & $\mathrm{I}_{2}$ & 2.05 & 2.48 \\
\hline & $\mathrm{I}_{3}$ & 2.32 & 3.19 \\
\hline \multicolumn{4}{|l|}{ Lateral tertip biçimleri } \\
\hline & Çift sıra $\left(D_{1}\right)$ & $2.40 \mathrm{~ns}$ & $3.32 \mathrm{~ns}$ \\
\hline & Salkım $\left(D_{2}\right)$ & 2.25 & $2.90 \mathrm{~ns}$ \\
\hline \multicolumn{4}{|c|}{$\overline{\text { Sulama suyu miktarları }}$} \\
\hline & $\mathrm{I}_{1}$ & $2.27 \mathrm{~ns}$ & $2.84 \mathrm{~ns}$ \\
\hline & $\mathrm{I}_{2}$ & 2.34 & 3.26 \\
\hline & $\mathrm{I}_{3}$ & 2.36 & 3.24 \\
\hline
\end{tabular}

ns: önemsiz

\section{Sonuç}

Tekirdağ koşullarında farklı lateral tertip biçiminin ve farklı sulama uygulamalarının ceviz ağaçlarının su kullanımı ve vejetatif gelişme parametrelerine olan etkilerinin belirlenmesi yönelik araştırma, 2015 ve 2016 yıllarında yürütülmüsşür. Araştırmada A sınıfı buharlaşma kabından ölçülen buharlaşma değerlerinin $\% 50,100$ ve 125 'inin uygulandığı üç farklı sulama suyu uygulaması gerçekleştirilmiştir. Araştırmanın yürütüldügü iki yıl boyunca ölçülen ceviz ağaçlarının bitki su tüketimi değerleri birlikte incelendiğinde uygulanan sulama suyu miktarı ile ölçülen bitki su tüketimi arasında doğrusal bir ilişki elde edilmiştir. Diğer yandan farklı lateral tertip biçimleri uygulaması altında ise birbirlerine yakın bitki su tüketimi değerleri ölçülmüştür. 2015 yılında ölçüm periyodu boyunca 209.0 mm yağış ölçülmüş̧ür. Bu yağış miktarının büyük bir kısmının Haziran ayı öncesinde ve Eylül ayından sonra gerçekleşmiştir. Bu yıl özellikle Temmuz ve Ağustos aylarında buharlaşma miktarının yüksek olduğu belirlenmiştir. 2015 yılında açık su yüzeyi buharlaşması değerlerinin \%100' ünün uygulandığı deneme konusuna $595.6 \mathrm{~mm}$ sulama suyu uygulanmış ve $858.9 \mathrm{~mm}$ ile $862.2 \mathrm{~mm}$ (ortalama $860.6 \mathrm{~mm}$ ) bitki su tüketimi ölçülmüştür. Ayrıca, ceviz ağaçlarının birinci yaşında yüksek bitki su tüketimi değerinin eldesi, fidan döneminden yeni çıkan ağaçların örtü yüzdesinin düşük olması ve dolayısıyla uygulanan sulama suyu miktarında buharlaşma kayıplarının önemli miktarda olduğu şeklinde açıklanabilir. 2016 yllında ise 2015 yllına göre daha düşük yağış değerleri ölçülmesine $(81,0 \mathrm{~mm})$ karşın açık su yüzeyi buharlaşması değerlerinin $\% 100$ ' ünün uygulandığ deneme konusuna $585.9 \mathrm{~mm}$ sulama suyu uygulanmış ve $757.5 \mathrm{~mm}$ ile $764.5 \mathrm{~mm}$ (ortalama $761.0 \mathrm{~mm}$ ) bitki su tüketimi ölçülmüştür. 2016 yılında 2015 yılından daha düşük bitki su tüketimi değerlerinin elde edilmesi, ölçüm periyodu boyunca daha düşük yağış değerlerinin elde edilmesi, diğer yandan ceviz ağaçlarının örtü yüzdesinin artması ile topraktan olan buharlaşma miktarının azalması ile açıklanabilir. 
Çizelge 5. Deneme konularından ölçülen ceviz ağaçları vejetatif gelişme parametreleri (2016)

Table 5. The measured walnut vegetative growth parameters for treatments (2016)

\begin{tabular}{|c|c|c|c|c|c|c|}
\hline \multicolumn{2}{|c|}{ Deneme Konuları } & \multirow{2}{*}{$\begin{array}{c}\text { Sulama sezonu } \\
\text { sonunda ölçülen } \\
\text { gövde çapı değerleri } \\
(\mathrm{cm})\end{array}$} & \multirow{2}{*}{$\begin{array}{c}\text { Sulama sezonu } \\
\text { sonunda elde edilen } \\
\text { gövde kesit alanı artış } \\
\text { değerleri }\left(\mathrm{cm}^{2}\right)\end{array}$} & \multirow{2}{*}{$\begin{array}{c}\text { Sulama sezonu } \\
\text { sonunda ölçülen taç } \\
\text { yüksekliği değerleri } \\
(\mathrm{m})\end{array}$} & \multirow{2}{*}{$\begin{array}{c}\text { Sulama sezonu } \\
\text { sonunda ölçülen taç } \\
\text { genişliği değerleri } \\
\text { (m) }\end{array}$} & \multirow{2}{*}{$\begin{array}{l}\text { Sulama sezonu } \\
\text { sonunda elde } \\
\text { edilen taç hacm } \\
\text { değerleri }\left(\mathrm{m}^{3}\right)\end{array}$} \\
\hline Lateral tertip biçimi & $\begin{array}{l}\text { Sulama suyu } \\
\text { miktarları }\end{array}$ & & & & & \\
\hline \multirow[t]{3}{*}{ Çift sıra $\left(D_{1}\right)$} & $\mathrm{I}_{1}$ & $4.05 \mathrm{~ns}$ & $9.17 \mathrm{~ns}$ & $1.68 \mathrm{~ns}$ & $1.16 \mathrm{~ns}$ & $0.91 \mathrm{~ns}$ \\
\hline & $\mathrm{I}_{2}$ & 4.73 & 12.15 & 1.99 & 1.27 & 1.31 \\
\hline & $\mathrm{I}_{3}$ & 4.33 & 10.20 & 1.70 & 1.23 & 1.12 \\
\hline \multirow{3}{*}{$\begin{array}{l}\text { Salkım } \\
\left(\mathrm{D}_{2}\right)\end{array}$} & $\mathrm{I}_{1}$ & 4.00 & 8.17 & 1.70 & 1.19 & 0.98 \\
\hline & $\mathrm{I}_{2}$ & 4.31 & 11.27 & 2.04 & 1.34 & 1.43 \\
\hline & $\mathrm{I}_{3}$ & 4.51 & 11.70 & 2.07 & 1.35 & 1.57 \\
\hline \multicolumn{7}{|l|}{ Lateral tertip biçimleri } \\
\hline & Çift sıra $\left(D_{1}\right)$ & $4.37 \mathrm{~ns}$ & $10.51 \mathrm{~ns}$ & $1.79 \mathrm{~ns}$ & $1.22 \mathrm{~ns}$ & $1.11 \mathrm{~ns}$ \\
\hline & $\operatorname{Salkım}\left(\mathrm{D}_{2}\right)$ & 4.27 & 10.38 & 1.94 & 1.29 & 1.33 \\
\hline \multicolumn{7}{|c|}{ Sulama suyu miktarları } \\
\hline & $\mathrm{I}_{1}$ & $4.27 \mathrm{~ns}$ & $8.67 \mathrm{~ns}$ & $1.69 \mathrm{~ns}$ & $1.18 \mathrm{~ns}$ & $0.95 \mathrm{~ns}$ \\
\hline & $\mathrm{I}_{2}$ & 4.52 & 11.71 & 2.02 & 1.31 & 1.33 \\
\hline & $\mathrm{I}_{3}$ & 4.42 & 10.95 & 1.89 & 1.29 & 1.35 \\
\hline
\end{tabular}

ns: önemsiz

Farklı lateral tertip biçimi ve farklı sulama düzeylerinin ceviz ağaçlarının vejetatif gelişme parametrelerine olan etkisini belirlemek için sulamanın tamamlanıp bitkilerin kış dinlenmesine geçtiği zaman ceviz ağaçlarında ölçümler yapılmıştır. Bu parametrelerden gövde çapı her iki yılda ölçülmüş gövde çap değişimleri ile hesaplanan gövde kesit alanı artış değerleri elde edilmiştir. Diğer parametrelerden ise taç yüksekliği, taç genişliği ve bu değerlerden hesaplanan taç hacmi sonuçları belirlenmiştir. Elde edilen bu sonuçlar istatistiksel olarak değerlendirilmiştir. Varyans analiz sonuçlarında, farklı lateral tertip biçiminin ve uygulanan sulama suyu miktarlarının ceviz ağaçlarının (1-2 yaş) vejetatif gelişme parametrelerini etkileme düzeyinin istatistiki olarak önemli olmadı̆̆ belirlenmiştir. Tüm bu veriler 1şı̆̆ında, özellikle araştırma sonucunda elde edilen bitki su tüketimi değerlerinin ceviz ağaçlarının sulanmasına yönelik temel bilgileri oluşturacaktır. Diğer yandan, ülkemiz koşullarında ceviz ağaçlarının su kullanımına yönelik yürütülen ilk çalışmalardan biri olan bu araştırmanın ülkedeki üreticilere ve bu konuda bilimsel araştırma yürütecek uzmanlara yararlı olacağı düşünülmektedir. 


\section{Kaynaklar/References}

Anonim. (2012). Ceviz Eylem Planı 2012-2016. T.C. Orman ve Su işleri Bakanlığı, Orman Genel Müdürlüğü Yayınları.

Anonim. (2016). Bitkisel Üretim İstatistikleri. Türkiye İstatistik Kurumu. https://biruni.tuik.gov.tr/bitkiselapp/bitkisel.zul

Çelik, M. (1988). Ankara Koşullarında Williams, Ankara Akça ve Şeker Armut Çeşitleri İçin En Uygun S.Ö. Ayva Anaçlarının Seçimi Üzerine Bir Araştırma. Ankara Üniversitesi Ziraat Fakültesi Yayınları: 1075 (578), Ankara.

FAO. 2014. FAOSTAT. 'Food and Agriculture Organization of the United Nations'. http://www.fao.org/faostat/en/\#data/QC

Hu, Q., Ma, Y., He, J., Zhang, Q., Hong, M. (2010). Effect of drip irrigation and micro -sprinkler irrigation on water consumption, yields and quality of walnut. Journal of Water Resources and Water Engineering, 1:020.

Huabing, M., Meimei, L., Junjie, R., Baoguo, L., Guohoi, Q. (2014). Effects of different irrigation amounts on water use of precocious walnuts. Applied Mechanics and Materials. Vol: 651- 653, 1423-1431

Kanber, R. (1997). Sulama. Çukurova Üniversitesi Ziraat Fakültesi Ders Kitabı, Genel Yayın No. 174, Ders Kitapları Yayın No. 52, 530s, Adana.

Kanber, R., Steduto, P., Aydın, Y., Ünlü, M., Özmen, S., Çetinkökü, Ö., Özekici, B., Diker K., Sezen, M. S. (2004). Damla sulama sistemiyle fertigasyon uygulamalarının antepfıstığında gelişme, verim ve periyodisiteye etkisinin incelenmesi. Tübitak, TARP 1825.

Keller, J., Bliesner, R. D. (1990). Sprinkle and Trickle Irrigation.Van Nostrand Reinhold.

Köksal, A. I. (1982). Bazı Elma ve Armut Anaçları ile Büların Üzerine Aşılı Önemli Kültür Çeşitleri Arasındaki GA ve ABA Benzeri Maddelerim Değişimleri Üzerine Araştırmalar. Ankara Üniversitesi Ziraat Fakültesi Yayınları: 800 (473), Ankara.

Köksal, A.I., Yıldırım, O., Dumanoğlu, H., Güneş, N., Kadayıfçı, A. (1996). Bodur Elma Çeşitlerinde Farklı Sulama Yöntemi ve Sulama Suyu Miktarlarının Gelişme Verim ve Kaliteye Etkisi. TÜBİTAK Proje No: TOAG-901.

Li, H.B., Mu, Z.X., Hong, M., Zheng, B. (2013). Optimization of irrigation methods for grown walnut in arid and semi arid regions. Water Saving Irrigation, 6, 010 .

Nakayama, F.S, Bucks, D. A. (1986). Trickle Irrigation for Crop Production. Elsevier, Amsterdam.

Şen, S.M. (2011). Ceviz. ÜÇM Yayıncılık, 220 s, Ankara.

Ünver, H., Sakar, E. (2011). türkiye'de ceviz yetiştiriciliğin durumu ve yapılan seleksiyon çalışmaları. Harran Üniv. Zir. Fak. Dergisi,15 (3): 61-69.

Walker, W.R., Skogerboe, G.V. (1987). Surface Irrigation. Theory and Practice. Prentice- Hall, Englewood Cliffs, 375 pp, New Jersey.

Yıldırım, M. (2004). Damla Yöntemiyle Sulanan Erik Ağaçlarında Farklı Sulama Programlarının Ağaç Gelişmesi, Meyve Verimi ve Kalitesi Üzerine Etkileri. Ankara Üniversitesi Fen Bilimleri Enstitüsü (Doktora Tezi), Ankara.

Yıldırım, O. (2008). Sulama Sistemlerinin Tasarımı. Ankara Üniversitesi Ziraat Fakültesi Yayın No: 1565, Ankara.

Yurtsever, N. (1984). Deneysel İstatistik Metotları. Köy Hizmetleri Genel Müd. Yayınları No. 56, Ankara. 